\title{
The globin gene family of the cephalochordate amphioxus: implications for chordate globin evolution
}

\author{
Bettina Ebner ${ }^{1}$, Georgia Panopoulou ${ }^{2}$, Serge N Vinogradov ${ }^{3}$, Laurent Kiger ${ }^{4}$, Michael C Marden ${ }^{4}$, \\ Thorsten Burmester ${ }^{5}$, Thomas Hankeln ${ }^{1 *}$
}

\begin{abstract}
Background: The lancelet amphioxus (Cephalochordata) is a close relative of vertebrates and thus may enhance our understanding of vertebrate gene and genome evolution. In this context, the globins are one of the best studied models for gene family evolution. Previous biochemical studies have demonstrated the presence of an intracellular globin in notochord tissue and myotome of amphioxus, but the corresponding gene has not yet been identified. Genomic resources of Branchiostoma floridae now facilitate the identification, experimental confirmation and molecular evolutionary analysis of its globin gene repertoire.
\end{abstract}

Results: We show that $B$. floridae harbors at least fifteen paralogous globin genes, all of which reveal evidence of gene expression. The protein sequences of twelve globins display the conserved characteristics of a functional globin fold. In phylogenetic analyses, the amphioxus globin BflGb4 forms a common clade with vertebrate neuroglobins, indicating the presence of this nerve globin in cephalochordates. Orthology is corroborated by conserved syntenic linkage of BflGb4 and flanking genes. The kinetics of ligand binding of recombinantly expressed $\mathrm{BfIGb4}$ reveals that this globin is hexacoordinated with a high oxygen association rate, thus strongly resembling vertebrate neuroglobin. In addition, possible amphioxus orthologs of the vertebrate globin $X$ lineage and of the myoglobin/cytoglobin/hemoglobin lineage can be identified, including one gene as a candidate for being expressed in notochord tissue. Genomic analyses identify conserved synteny between amphioxus globincontaining regions and the vertebrate $\beta$-globin locus, possibly arguing against a late transpositional origin of the $\beta$-globin cluster in vertebrates. Some amphioxus globin gene structures exhibit minisatellite-like tandem duplications of intron-exon boundaries ("mirages"), which may serve to explain the creation of novel intron positions within the globin genes.

Conclusions: The identification of putative orthologs of vertebrate globin variants in the $B$. floridae genome underlines the importance of cephalochordates for elucidating vertebrate genome evolution. The present study facilitates detailed functional studies of the amphioxus globins in order to trace conserved properties and specific adaptations of respiratory proteins at the base of chordate evolution.

\section{Background}

Globins are heme-containing proteins that bind $\mathrm{O}_{2}$ and other gaseous ligands between the iron atom at the center of the porphyrin ring and a histidine residue of their polypeptide chain [1]. In addition to supporting aerobic metabolism of cells by providing $\mathrm{O}_{2}$ supply, globins

\footnotetext{
* Correspondence: hankeln@uni-mainz.de

${ }^{1}$ Institute of Molecular Genetics, Johannes Gutenberg-University, D-55099 Mainz, Germany

Full list of author information is available at the end of the article
}

fulfill a broad range of other functions, including $\mathrm{O}_{2}$ sensing, detoxification of harmful reactive oxygen species (ROS), the generation of bioactive gas molecules like NO and others [2]. Thus it is not surprising that the versatile globins are found from bacteria to fungi, protists, plants, and most animal groups [3].

The intensively studied hemoglobins $(\mathrm{Hb})$ and myoglobins $(\mathrm{Mb})$ are present in almost all vertebrate species, being responsible for $\mathrm{O}_{2}$ transport and storage, but also the production and elimination of NO $[4,5]$. Some years

\section{Biomed Central}


ago, the vertebrate globin gene family was expanded by the discovery of two additional globin types, neuroglobin and cytoglobin [6-8]. Neuroglobin ( $\mathrm{Ngb})$ is preferentially expressed in neurons and endocrine cells, and its expression patterns suggest an association with oxidative metabolism and the presence of mitochondria $[9,10]$. Cytoglobin $(\mathrm{Cygb})$ is expressed in fibroblast-related cell types and distinct neuronal cell populations $[11,12]$. The exact physiological function(s) of both proteins are still uncertain, and several, partially contradictory hypotheses have been proposed, including functions in $\mathrm{O}_{2}$ supply, ROS detoxification, signal transduction and inhibition of apoptosis [13]. In the biomedical field, Ngb and Cygb have created considerable interest because these proteins appear to convey protection to cells and organs, e.g. after ischemia/reperfusion injury of the brain [14-16].

Due to the high number of available sequences, globins have become a popular model for the investigation of gene and gene family evolution [17]. In vertebrates, there are multiple $\alpha-H b$ and $\beta-H b$ genes, which form distinct clusters. In birds and mammals, the $\alpha-H b$ and $\beta-H b$ gene loci are found on separate chromosomes, while these loci are joined in fish and amphibians [18-20]. $M b, N g b$ and $C y g b$, however, are typically single copy genes that are not associated with any other globin locus. Molecular phylogenetic studies and genomic comparisons may permit more refined insights into the function of Ngb and Cygb. Both of these proteins and genes are subject to strong purifying selection in all vertebrates studied so far, suggesting an essential cellular role [21,22]. Phylogenetic trees have shown that Ngb is distantly related to nerve hemoglobins in invertebrate worms, suggesting that its function is required in nerve cells of prototomian and deuterostomian animals, which diverged more than 600 million years ago [6]. Cygb, however, is a paralog of the muscle-specific $\mathrm{Mb}$ and may have been created by a duplication event only after the separation of agnathan and gnathostomian vertebrates about 450 million years ago [7]. In addition to the widespread Ngb and Cygb, some vertebrate lineages possess specific additional globin variants of unknown function, named globin $\times(\mathrm{GbX})$ in fish and frogs, globin $\mathrm{Y}(\mathrm{GbY})$ in frogs, lizards, and monotreme mammals and globin E (GbE) in birds [20,23-25]. To evaluate the resulting scenarios of vertebrate globin evolution, and to identify important, evolutionary conserved protein structure and ligand binding characteristics of human Ngb and Cygb, it is mandatory to identify and study candidate globin orthologs in non-vertebrate taxa.

In the 'new deuterostome phylogeny' [26,27], urochordates (tunicates) appear to be the closest relatives to vertebrates, while the cephalochordate amphioxus (lancelet), believed for a long time to be the vertebrate sister taxon, now appears to be basal to the vertebrate/ tunicate clade. We have previously reported the globin gene repertoire of the tunicate Ciona intestinalis (sea squirt), consisting of at least four globins, clustered in a monophyletic clade. These genes are about equally distantly related to the vertebrate $\mathrm{Ngb}$ and GbX lineage, so that no clear orthology could be established $[23,28]$. In cephalochordates, the existence of a globin protein in notochord cells and myotome tissue of Branchiostoma californiense and B. floridae has been demonstrated by biochemical studies [29]. This intracellular globin is a dimer consisting of $19 \mathrm{kDa}$ subunits with a high $\mathrm{O}_{2}$ affinity $\left(P_{50}=0.27\right.$ Torr, $\left.15^{\circ} \mathrm{C}\right)$. Because of this high affinity and the absence of cooperativity, a possible role of the globins in facilitating diffusion of $\mathrm{O}_{2}$ into the notochord cells was discussed [29]. However, recent publications based on the genome sequence of $B$. floridae have yielded no hint at the presence of globin genes in this most basal chordate taxon $[27,30]$. To address this shortcoming, here we report the genomic organization of B. floridae globin genes (BflGb) and their evolutionary implications.

\section{Methods}

\section{Database searches and sequence analyses}

BLAST searches [31] were performed on whole genome shotgun data from the NCBI trace archive [32] and the Branchiostoma floridae genome project versions 1.0 and 2.0 at the JGI [33]. Searches of expressed sequence tags (ESTs) were performed using the B. floridae cDNA resource [34,35] and the NCBI EST database [36]. Nucleotide sequences were extracted from databases, assembled and translated using the DNAstar 5.08 program package (Lasergene).

Pairwise percentage sequence identities and similarities of proteins were calculated using the Matrix Global Alignment Tool (MatGAT) version 2.0 [37] using a PAM250 scoring matrix. Dotplots for detecting repeat structures were made using zPicture [38]. Prediction of subcellular localization of proteins was done by PSORT II [39]. N-myristoylation sites were predicted by Myristoylater [40].

\section{Molecular phylogeny}

The conceptionally translated amino acid sequences of the $B$. floridae globins were manually added to an alignment of selected globin sequences [6,7]. The sequences used are Homo sapiens neuroglobin (HsaNGB [GenBank:AJ245946]), cytoglobin (HsaCYGB, [GenBank: AJ315162]), myoglobin (HsaMB [GenBank:M14603]), hemoglobin $\alpha$ (HsaHBA [GenBank:J00153]), and $\mathrm{Hb} \beta$ (HsaHBB [GenBank:M36640]); Mus musculus Ngb (MmuNgb [GenBank:AJ245946]), Cygb (MmuCygb [GenBank:AJ315163]) and Mb (MmuMb [GenBank: P04247]); Ornithorhynchus anatinus GbY (OanGbY 
[GenBank:AC203513]; Gallus gallus Ngb (GgaNgb [GenBank:AJ635192]), GbE (GgaGbE [GenBank: AJ812228]); Taeniopygia guttata GbE (TguGbE [XM_002196350]); Xenopus tropicalis GbX (XtrGbX [GenBank:AJ634915]), Hb a (XtrHbA [GenBank: P07428]), Hb $\beta$ (XtrHbB [GenBank:P07429]), GbY (XtrGbY [GenBank:BC158411]); Xenopus laevis GbY (XlaGbY [GenBank:AJ635233]); Danio rerio Ngb (DreNgb [GenBank:AJ315610]), GbX (DreGbX [GenBank:AJ635194]), Cygb1 (DreCygb1 [GenBank: AJ320232]), Mb (DreMb [GenBank:AAR00323]); Carassius auratus GbX (CauGbX [GenBank:AJ635195]); Myxine glutinosa $\mathrm{Hb} 1$ (MglHb1 [GenBank:AF156936]), Hb3 (MglHb3 [GenBank:AF184239]); Lampetra fluviatilis $\mathrm{Hb}$ (LflHb [GenBank:P02207]); Medicago sativa leghemoglobin (MsaLegHb [GenBank:P09187]); Lupinus luteus leghemoglobin (LluLegHb [GenBank:P02240]); Casuarina glauca $\mathrm{Hb} 1$ (CglHb1 [GenBank:P08054]). In our deuterostome globin analysis, we refrained from inclusion of protostome globin sequences, because these tend to behave polyphyletically in the tree (Additional File 1), possibly due to long-branch attraction artifacts. Our trees were therefore rooted by plant globin sequences.

Phylogenetic tree reconstructions were performed using MrBayes version $3.1[41,42]$ using the WAG model of amino acid evolution [43] assuming a gamma distribution of rates, as suggested by analysis of the alignment with ProtTest version 1.2.7 [44]. Metropoliscoupled Markov chain Monte Carlo sampling was performed with one cold and three heated chains that were run for up to 3,000,000 generations. Trees were sampled every $10^{\text {th }}$ generation and 'burn in' was set to 9,000 . Maximum likelihood-based phylogenetic analysis was performed by RAxML version 7.2.3 [45] assuming the WAG model and gamma distribution of substitution rates. The resulting tree was tested by bootstrapping with 100 replicates.

\section{RT-PCR confirmation of $B$. floridae globin coding sequences}

Adult specimens of $B$. floridae were collected at Tampa Bay, Florida, USA. Total RNA was isolated from whole animals using the RNeasy Kit according to the supplier's instructions (Qiagen). To remove genomic DNA a DNase I digestion step was included in the preparation. Reverse transcription of $0.5 \mu \mathrm{g}$ total RNA was performed using SUPERSCRIPT II reverse transcriptase (Invitrogen) with an oligo(dT) primer. Using one-tenth of a cDNA reaction and $2 \mathrm{U}$ Taq DNA polymerase (Sigma) the complete or partial coding sequences of the bioinformatically predicted globin genes were amplified in a standard PCR protocol. Missing 5' and 3' regions were obtained using the GeneRacer Kit with SUPERSCRIPT III reverse transcriptase (Invitrogen). PCR products were sequenced directly or were cloned into the pGEM-Teasy vector system (Promega) and both strands were sequenced by a commercial sequencing service (StarSeq). Nucleotide sequences were deposited in the database under the accession numbers listed in Table 1.

\section{Recombinant globin expression and characterization}

Amphioxus globin variant $\mathrm{BflGb} 4$ coding sequence was isolated by RT-PCR, cloned into prokaryotic expression vector $\mathrm{pET} 15 \mathrm{~b}$, verified by re-sequencing and ultimately expressed and affinity-purified from E. coli BL21pLys host cells by a Ni-NTA Superflow column (Qiagen). The kinetics of ligand binding by the flash photolysis method was measured to determine functional properties of the BflGb4 globin. After photolysis of the CO form, the subsequent completion of rebinding of the $\mathrm{CO}$ and any internal protein ligands provides information on the association and dissociation rates. Samples of $10 \mu \mathrm{M}$ protein, on a heme basis, were placed under a controlled atmosphere of $\mathrm{CO}$, oxygen or a mixture of both ligands, and photolyzed with $10 \mathrm{~ns}$ pulses at $532 \mathrm{~nm}$.

\section{Results and Discussion}

Identification and annotation of $B$. floridae globin genes

Systematic TBlastN searches were carried out on the database of the $B$. floridae genome project versions 1.0 and 2.0 at the JGI [27] and the Branchiostoma cDNA resource [34] and complemented with the data of the whole genome shotgun sequences at the NCBI trace archive. Using vertebrate $\mathrm{Ngb}$ and $\mathrm{Cygb}$ sequences as query, fifteen distinct bona fide globin genes were identified in Branchiostoma genome v. 2.0, which reports a single haplotype at each locus [27] (Figure 1 Table 1). This is substantially more than the four gene copies identified in the tunicate C. intestinalis [28] but less than the largest globin gene families known from invertebrates (C. elegans: 33 genes [46]; Chironomus midges: 30-40 genes [47]). The reason for the higher globin gene copy number in Branchiostoma vs. Ciona is unknown. It may reflect differences in life-style (sand-burrowing vs. sessile) and/or the threefold higher genome size in amphioxus compared to the tunicate, which is thought to have undergone substantial gene loss [27]. Eight of the 15 gene models annotated in the database required extensive changes, which were performed by visual inspection of DNA sequencing traces, comparative amino acid sequence alignments and after cDNA verification by RT-PCR. One additional gene model (BRAFL DRAFT_81713) contains 86 amino acids of globinrelated sequence embedded in a large protein of 1323 residues, annotated to be a calpain-like protease. We do not include this aberrant structure in the present analysis of bona fide globins. 
Table 1 Overview on amphioxus globin genes

\begin{tabular}{|c|c|c|c|c|c|c|c|}
\hline \multirow[t]{2}{*}{ globin } & \multirow[t]{2}{*}{$\begin{array}{l}\text { gene designation } \\
\text { (Brafl genome V2.0) }\end{array}$} & \multirow[t]{2}{*}{$\begin{array}{l}\text { alternative haplotype (Brafl } \\
\text { genome version 1.0) }\end{array}$} & \multirow[t]{2}{*}{$\begin{array}{l}\text { identity/similarity of } \\
\text { haplotype proteins }\end{array}$} & \multicolumn{2}{|c|}{ EST data } & \multicolumn{2}{|c|}{$\begin{array}{l}\text { RT-PCR confirmation } \\
\text { of CDS }\end{array}$} \\
\hline & & & & $\begin{array}{l}\text { Acc.no. } \\
\text { GenBank }\end{array}$ & expression & $\begin{array}{l}\text { Acc.no. } \\
\text { GenBank }\end{array}$ & $\begin{array}{l}\text { coverage } \\
\text { of CDS }\end{array}$ \\
\hline BflGb1 & $\begin{array}{l}\text { BRAFLDRAFT_98913 } \\
\text { [GenelD:7251500] }\end{array}$ & BRAFLDRAFT_92353 & $98.5 / 99.5 \%$ & - & - & FN773089 & complete \\
\hline BflGb2 & $\begin{array}{l}\text { BRAFLDRAFT_98914 } \\
\text { [GenelD:7251501] }\end{array}$ & BRAFLDRAFT_92354 & $95.9 / 97.3 \%$ & - & - & FN773090 & complete \\
\hline BflGb3 & $\begin{array}{l}\text { BRAFLDRAFT_99970 } \\
\text { [GenelD:7252875] }\end{array}$ & BRAFLDRAFT_72350 & $99.4 / 100 \%$ & - & - & FN773091 & partial \\
\hline BflGb4 & $\begin{array}{l}\text { BRAFLDRAFT_74626 } \\
\text { [GenelD:7236365] }\end{array}$ & BRAFLDRAFT_84888 & $97.9 / 98.9 \%$ & - & - & FN773092 & complete \\
\hline BflGb5 & $\begin{array}{l}\text { BRAFLDRAFT_96953 } \\
\text { [GenelD:7248969] }\end{array}$ & BRAFLDRAFT_110609 & $97.8 / 98.9 \%$ & BW852078 & $\begin{array}{l}\text { neurula } \\
\text { whole animal }\end{array}$ & FN773093 & complete \\
\hline BflGb6 & $\begin{array}{l}\text { BRAFLDRAFT_74265 } \\
\text { [GenelD:7230831] }\end{array}$ & BRAFLDRAFT_96513 & $100 / 100 \%$ & - & - & FN773094 & partial \\
\hline \multirow[t]{4}{*}{ BflGb7 } & $\begin{array}{l}\text { not annotated in } \\
\text { database }\end{array}$ & not annotated in database & - & BW695259 & $\begin{array}{l}\text { adult whole } \\
\text { animal }\end{array}$ & FN773095 & complete \\
\hline & & & & BW701618 & $\begin{array}{l}\text { adult whole } \\
\text { animal }\end{array}$ & & \\
\hline & & & & BW702763 & $\begin{array}{l}\text { adult whole } \\
\text { animal }\end{array}$ & & \\
\hline & & & & BW704772 & $\begin{array}{l}\text { adult whole } \\
\text { animal }\end{array}$ & & \\
\hline BflGb8 & $\begin{array}{l}\text { BRAFLDRAFT_92393 } \\
\text { [GenelD:7215786] }\end{array}$ & BRAFLDRAFT_92377 & $97.6 / 99.4 \%$ & & & FN773096 & partial \\
\hline \multirow[t]{2}{*}{ BflGb9 } & $\begin{array}{l}\text { BRAFLDRAFT_96956 } \\
\text { [GenelD:7250575] }\end{array}$ & not annotated in database & - & BW696096 & $\begin{array}{l}\text { adult whole } \\
\text { animal }\end{array}$ & FN773097 & complete \\
\hline & & & & BW700672 & $\begin{array}{l}\text { adult whole } \\
\text { animal }\end{array}$ & & \\
\hline \multirow[t]{3}{*}{ BfIGb10 } & $\begin{array}{l}\text { BRAFLDRAFT_118076 } \\
\text { [GenelD:7214470] }\end{array}$ & BRAFLDRAFT_132915 & $97.2 / 98.6 \%$ & BW717063 & $\begin{array}{l}\text { adult whole } \\
\text { animal }\end{array}$ & FN773098 & complete \\
\hline & & & & BW695770 & $\begin{array}{l}\text { adult whole } \\
\text { animal }\end{array}$ & & \\
\hline & & & & BW698433 & $\begin{array}{l}\text { adult whole } \\
\text { animal }\end{array}$ & & \\
\hline \multirow[t]{12}{*}{ BfIGb11 } & $\begin{array}{l}\text { BRAFLDRAFT_127451 } \\
\text { [GenelD:7247920] }\end{array}$ & BRAFLDRAFT_133418 & $98.6 / 99.3 \%$ & BW709730 & $\begin{array}{l}\text { adult whole } \\
\text { animal }\end{array}$ & FN773099 & complete \\
\hline & & & & BW700901 & $\begin{array}{l}\text { adult whole } \\
\text { animal }\end{array}$ & & \\
\hline & & & & BW706678 & $\begin{array}{l}\text { adult whole } \\
\text { animal }\end{array}$ & & \\
\hline & & & & BW695940 & $\begin{array}{l}\text { adult whole } \\
\text { animal }\end{array}$ & & \\
\hline & & & & BW720248 & $\begin{array}{l}\text { adult whole } \\
\text { animal }\end{array}$ & & \\
\hline & & & & BW721930 & $\begin{array}{l}\text { adult whole } \\
\text { animal }\end{array}$ & & \\
\hline & & & & BW709489 & $\begin{array}{l}\text { adult whole } \\
\text { animal }\end{array}$ & & \\
\hline & & & & BW717166 & $\begin{array}{l}\text { adult whole } \\
\text { animal }\end{array}$ & & \\
\hline & & & & BW693523 & $\begin{array}{l}\text { adult whole } \\
\text { animal }\end{array}$ & & \\
\hline & & & & BW692993 & $\begin{array}{l}\text { adult whole } \\
\text { animal }\end{array}$ & & \\
\hline & & & & BW710133 & $\begin{array}{l}\text { adult whole } \\
\text { animal }\end{array}$ & & \\
\hline & & & & BW699215 & $\begin{array}{l}\text { adult whole } \\
\text { animal }\end{array}$ & & \\
\hline
\end{tabular}




\begin{tabular}{|c|c|c|c|c|c|c|c|}
\hline & & & & BW698534 & $\begin{array}{l}\text { adult whole } \\
\text { animal }\end{array}$ & & \\
\hline & & & & BW709034 & $\begin{array}{l}\text { adult whole } \\
\text { animal }\end{array}$ & & \\
\hline & & & & BW701461 & $\begin{array}{l}\text { adult whole } \\
\text { animal }\end{array}$ & & \\
\hline & & & & BW703104 & $\begin{array}{l}\text { adult whole } \\
\text { animal }\end{array}$ & & \\
\hline & & & & AU234573 & $\begin{array}{l}\text { notochord (B. } \\
\text { belcheri) }\end{array}$ & & \\
\hline BflGb12 & $\begin{array}{l}\text { BRAFLDRAFT_74222 } \\
\text { [GeneID:7230826] }\end{array}$ & not annotated in database & - & - & - & FN773100 & partial \\
\hline BflGb13 & $\begin{array}{l}\text { BRAFLDRAFT_66937 } \\
\text { [GeneID:7219951] }\end{array}$ & BRAFLDRAFT_111239 & $98.9 / 100 \%$ & - & - & FN773101 & complete \\
\hline BflGb14 & $\begin{array}{l}\text { BRAFLDRAFT_77082 } \\
\text { [GenelD:7215245] }\end{array}$ & not annotated in database & - & - & - & FN773102 & complete \\
\hline BflGb15 & $\begin{array}{l}\text { BRAFLDRAFT_90360 } \\
\text { [GeneID:7213766] }\end{array}$ & BRAFLDRAFT_90367 & $98.6 / 99.3 \%$ & - & - & FN773103 & complete \\
\hline
\end{tabular}

Gene models, corresponding haplotypes, identities and similarities of haplotype proteins, nucleotide evolution rates of haplotypes, evidence for gene expression by ESTs and accession numbers of CDNA sequences are listed.

Due to the still highly fragmented nature of the Branchiostoma genome draft, the picture of genomic organization of globin genes is currently incomplete. Only eight out of 15 gene copies co-localize to the same scaffold, with four globins being located on genomic scaffold 39 (BflGb1, BflGb2, BflGb8 and BflGb15). Here, $B f l G b 1$ and $B f l G b 2$ are situated in head-to-tail orientation only $2.3 \mathrm{~kb}$ apart from each other, and their amino acid similarity (83\%; Additional file 2) may suggest their origin by a relatively recent gene duplication. The distance between $B f l G b 2$ and $B f l G b 8$ is $276 \mathrm{~kb}$, between $B f l G b 8$ and $B f l G b 15$ even more than $4 \mathrm{Mbp}$, showing that amphioxus globin genes are widely disseminated instead of featuring the vertebrate-typical dense clustering. Genes $B f l G b 5$ and $B f l G b 9$ reside in head-to-head orientation separated by $40 \mathrm{kbp}$ on scaffold 132 of the genome draft. This annotation is inconsistent with data of the trace archive, showing a head-to-tail orientation indicated by paired-end read information. BflGb6 and BflGb12 reside on scaffold 89 at a distance of $8 \mathrm{Mbp}$. All other seven globin genes are located on individual genomic scaffolds (Figure 1).

\section{Protein sequence comparisons and allelic differences}

The lengths of the deduced Branchiostoma globin sequences (Figure 2) range from 138 amino acids (BflGb11), which is consistent with the average length of the globin fold of 140-150 amino acids, to 236 residues (BflGb14). Such elongations, observed in 11 of the 15 amphioxus globins, result from $\mathrm{N}$-and $\mathrm{C}$ terminal extensions of the globin fold. The functional relevance of these extensions, previously reported e.g. for vertebrate Cygb [7] and nematode globins [46], is unclear. However, computer predictions using the
PSORT II program [39] indicate that none of the amphioxus globins appears to contain a leader signal peptide, and all variants are predicted to be located in the cytoplasm. Notably, eight Branchiostoma globins (BflGb1, 2, 3, 6, 9, 12, 13, 14), five of which are phylogenetically related to vertebrate GbX (see below), possess a predicted $\mathrm{N}$-myristoylation site. This may suggest an at least transient interaction with the cell membrane, thereby precluding an oxygen-supply function of these globins.

The comparison of the conceptionally translated amino acid sequences of $B$. floridae globins with human $\mathrm{Ngb}$, Cygb and $\mathrm{Mb}$ shows the conservation of the typical functional residues of globins [1] in most of the amphioxus proteins, such as the distal histidine (amino acid position E7), the proximal histidine (F8) and the phenylalanine at CD1 (Figure 2). While the proximal histidine, which coordinates the heme iron atom, is conserved in all 15 putative globins, the distal histidine is replaced by leucine in BflGb6, 12 and 13. The same replacement was previously reported in globins of Glycera dibranchiata [48] and in nematodes [49,50]. It creates an unusually hydrophobic ligand-binding site and may reduce affinity for polar ligands like $\mathrm{O}_{2}$ [51]. The same Branchiostoma globin variants also show a change at amino acid position CD1 from phenylalanine to tryptophan, and BflGb3 displays an exchange of this residue by a tyrosine. Position CD1 (Phe) is even more conserved during globin evolution than the distal histidine. In human $\mathrm{Hb}$, substitutions of $\mathrm{CD} 1$ (Phe) to nonaromatic amino acids usually lead to unstable globins and oxygenation problems [1]. The functional consequences of the more conservative CD1 changes in amphioxus variants, however, are unclear. 


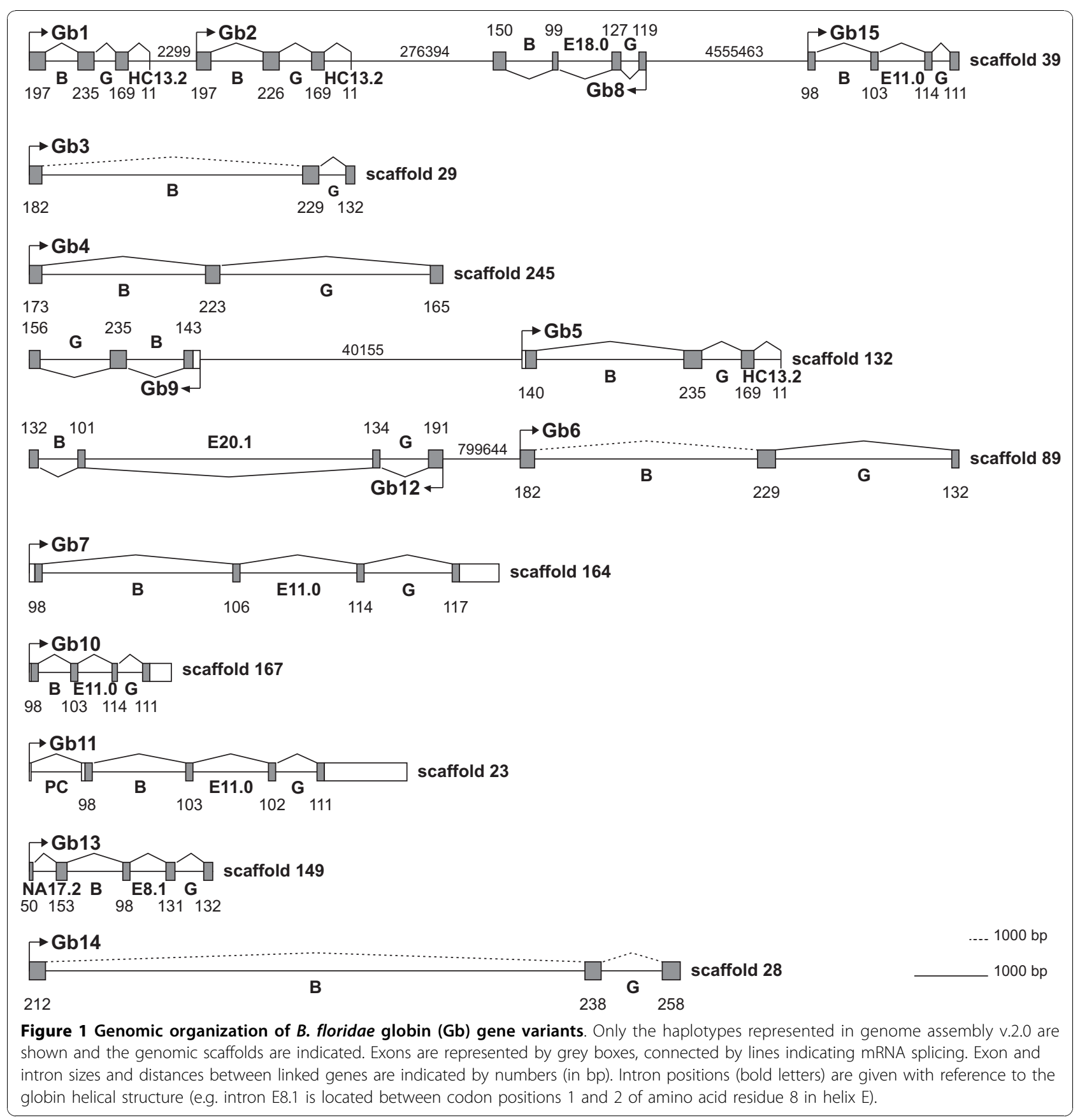

Pair-wise comparisons of the Branchiostoma globins display a substantial degree of divergence between the fifteen proteins. The most distant variants display a sequence identity of only $12 \%$ (BflGb11 and BflGb12) and a similarity of 31\% (BflGb11 and BflGb14). As such, they are as distinct as vertebrate $\mathrm{Mb}$ and $\mathrm{Cygb}$, which have separated before radiation of gnathostomes [21]. The most similar amphioxus paralogs (BflGb1 and BflGb2) have $60 \%$ sequence identity and $83 \%$ similarity (Additional file 2).
Possibly due to a large effective population size, $B$. floridae is highly heterozygous, and the genome sequencing of one specimen has revealed two haplotypes for two-thirds of the approximately 15,000 protein-coding loci [27]. We have identified allelic copies for 11 of the 15 globin variants (Table 1). Amino acid similarities/identities between alleles are high, ranging from 97/ $95 \%$ to $100 \%$. Taking into account these interallelic comparisons, the overall conservation of the globins on the protein level and the expression evidence on the 
RNA level (see below), we propose that most, if not all 15 globin gene variants in amphioxus can be considered active genes and at least 12 genes may encode functional globin proteins.

\section{Evidence for globin gene expression}

EST data provide evidence of transcription only for five Branchiostoma globin genes (BflGb5, BflGb7, BflGb9, $B f l G b 10$ and $B f l G b 11$; see Table 1). Represented by 17 EST entries, BflGb11 may be the most strongly expressed globin in whole adult animals. Based on the EST data and in silico-predictions, the coding regions of the fifteen genes were amplified by RT-PCR and completed by 5' and 3' RACE. Amplicons were cloned and sequenced for verification (Table 1). Together, these data demonstrate transcriptional expression of all Branchiostoma globin genes. Of special interest is the assignment of EST entry AU234573, representing BflGb11, to notochord tissue, as this facilitates further studies of the amphioxus globin components, which possibly serve to supply $\mathrm{O}_{2}$ to sustain the contractile function of notochord cells [29]. BflGb11, however, has a predicted molecular mass of $15 \mathrm{kDa}$ and thus may not represent the major $19 \mathrm{kDa}$ notochord globin fraction, as isolated biochemically by Bishop et al. [29]. Several other globin variants (e.g. BflGb5, 8, 9) have predicted molecular masses between 18 and $21 \mathrm{kDa}$.

\section{Identification of putative Branchiostoma orthologs to vertebrate globins}

The amino acid sequences of the 15 globin genes of Branchiostoma were included in an alignment of selected vertebrate and invertebrate globins $[6,7,28]$. Bayesian and maximum likelihood phylogenetic reconstruction revealed possible orthology relationships between amphioxus and vertebrate globins (Figure 3). Most importantly, BflGb4 forms a common clade with vertebrate Ngb. These two globins show 27\%/49\% identity/similarity. Corroborating evidence for orthology was obtained by inspecting the organization at the genomic level. Within vertebrates, the gene region containing $N g b$ is strongly conserved in gene order and arrangement [20,22]. The human $N G B$ gene resides on chromosome HSA14q24.3 between the genes for

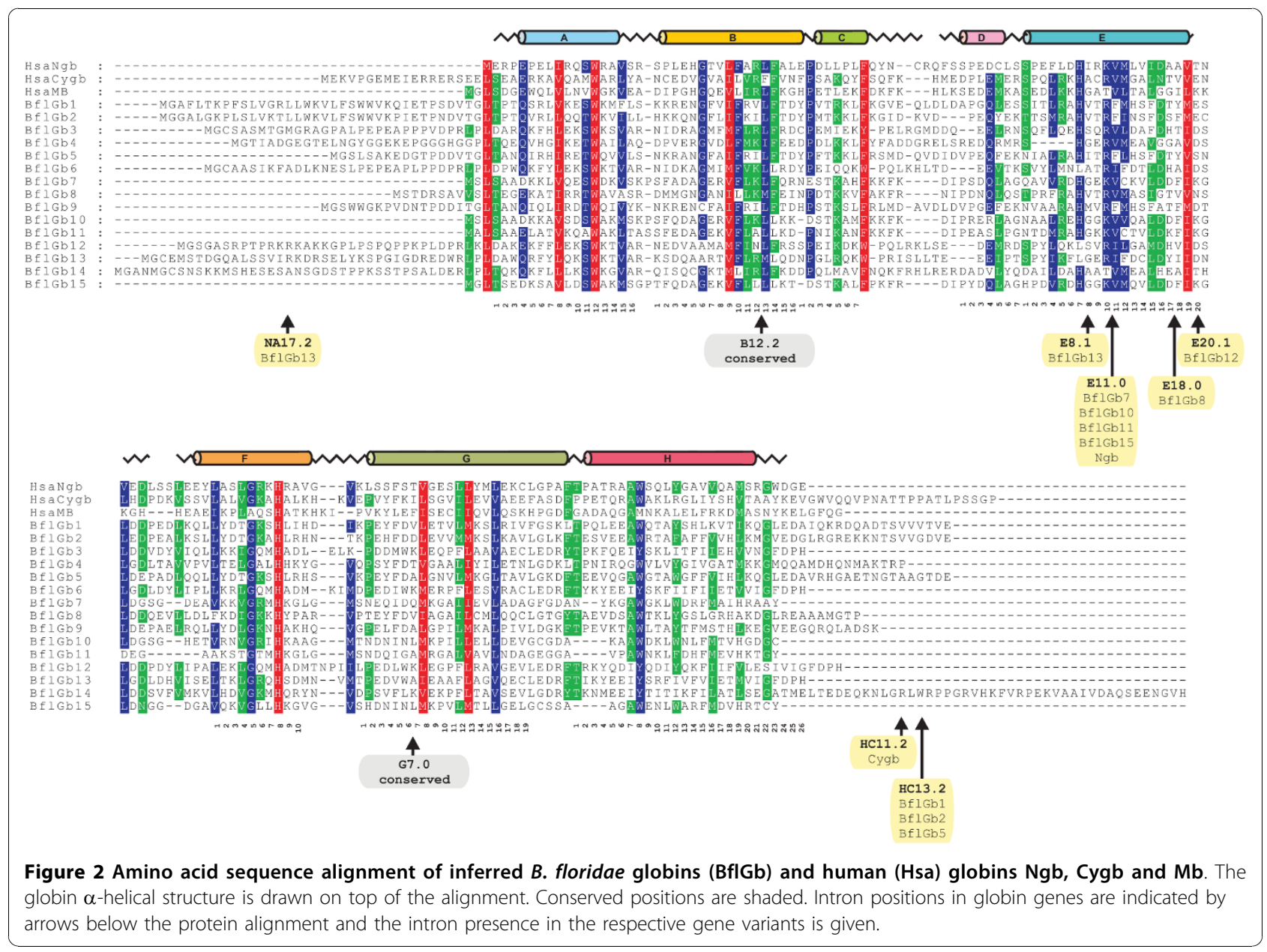


protein-O-mannosyltransferase 2 (POMT2) and transmembrane protein $63 \mathrm{C}$ (TMEM63C, previously termed DKFZp434P0111) [22]. While a TMEM63C ortholog was not detectable on genomic scaffold 245 containing $B f l G b 4$, the amphioxus orthologs of POMT2 and glutathione transferase zeta 1 (GSTZ1), located on the distal, telomeric side of the human $N G B$ gene, reside in close proximity to the $B f l G b 4$ gene (Figure 4). These findings are in agreement with Putnam et al. [27], who reported extensive micro-syntenic conservation of gene arrangement between amphioxus and humans on the whole-genome level. Together with the phylogeny, the data are convincing evidence that we have identified an ortholog of vertebrate $\mathrm{Ngb}$ in a basal chordate.

Phylogenetical interpretation of the tree reconstruction (Figure 3) further suggests that the monophyletic clade comprising BflGb3, BflGb6, BflGb12, BflGb13 and BflGb14 contains the putative orthologs of vertebrate GbX, a distant relative of the Ngb lineage, which is found only in fish and frogs, but not in birds and mammals $[20,23]$. This corroborates the scenario that GbX was already present in early chordates, but has been lost secondarily during tetrapod evolution. Syntenic conservation of $G b X$ flanking genes in Xenopus tropicalis and Tetraodon nigroviridis is restricted to three proximate genes encoding a pleckstrin domain containing protein (PLEKHG), phospholipase and signal recognition particle SRP12 [20]. Notably the genome of B. floridae revealed the linkage of a PLEKHG gene to $B f l G b 3$, substantiating the assumption of a possible $G b X$ orthology (Additional file 3).

Another amphioxus globin clade comprising BflGb1, $\mathrm{BflGb2}$, BflGb5 and BflGb9 is paralogous to all other vertebrate globins $(\mathrm{Hb}, \mathrm{Mb}, \mathrm{Cygb})$. This clade also groups with the four monophyletic globin variants from the genome of the tunicate C. intestinalis [28], which confirms our view that the $C$. intestinalis globins are not 1:1 orthologous to vertebrate globins.

A third monophyletic group of amphioxus globin variants, comprising BflGb7, BflGb10, BflGb11 and $\mathrm{BflGb15}$, joins the vertebrate Mb-Hb-Cygb-GbE-GbY lineage in the tree. It is noteworthy that this clade of amphioxus globins contains BflGb11, which may be expressed in notochord tissue, possibly serving the Mb-like role in $\mathrm{O}_{2}$ supply suggested by Bishop et al. [29]. Unfortunately, analysis of syntenic gene relationships of the $M b, C y g b$ and $H b$ loci $[19,22,52]$ did not generate further positive evidence for 1:1 gene orthology between amphioxus and vertebrate globins, possibly due to the fragmentary nature of the draft genome assembly. The absence of clear Cygb, $\mathrm{Mb}, \mathrm{Hb}$ and $\mathrm{GbE} / \mathrm{Y}$ orthologues in Branchiostoma may confirm that the gene duplications, which gave rise to these diverse vertebrate globin types, indeed happened after the split of cephalochordates and the vertebrate ancestor [7]. Nevertheless, the phylogenetic predictions will facilitate guided functional comparisons of cephalochordate and vertebrate globins.

\section{Implications for the evolution of the ancestral vertebrate globin gene cluster}

According to the current model of vertebrate globin evolution, the mammalian $\alpha-H b s$ constitute the ancestral vertebrate globin gene locus, while the $\beta$-cluster is the result of a transposition of globin genes into a region containing olfactory receptor (OR) genes [24,52]. Looking deeper into the evolutionary past, Wetten et al. [53] suggested a common origin of the vertebrate $\alpha-H b$ locus and two globin gene-containing regions in the $C$. intestinalis genome, as evidenced by the syntenic relationships of three globin-flanking genes. However, these genes do not show linkage to globins in the amphioxus genome. Wetten et al. [53] therefore proposed that they were secondarily linked to globin genes by a fusion of conserved genomic linkage groups (CLGs 3, 15 and 17) [27] to produce the ancestor of the vertebrate $\alpha-H b$ locus before the divergence of urochordates and vertebrates. Our own analyses of gene synteny, however, do not provide support for this model, since we could not detect any of the $B$. floridae globin genes within the respective CLGs. Instead, we find that Branchiostoma globins $B f l G b 5$ and 9 reside on the same genomic scaffold as the amphioxus orthologue of integrin-linked kinase ( $I L K)$, a conserved flanking gene of the $\beta-H b$ cluster in men, chicken and marsupials [24].

Additionally, a detailed inspection of the CLG's architecture [27] reveals that the amphioxus genomic scaffold including $B f l G b 1,2,8$ and 15 corresponds to human chromosomal region 11p15.4-15.5, the location of the $\beta-H b$ cluster in man. Of course, this hypothetical ancient orthology is at odds with the transpositional model for a more recent origin of the $\beta-H b$ locus during vertebrate evolution (the olfactory receptor genes are dispersed in amphioxus [54], and thus cannot help to clarify the evolutionary events). Clearly, a reliable reconstruction of the pre-vertebrate globin loci will require the analysis of additional deuterostome genomes.

\section{Kinetics of ligand binding of the putative Ngb ortholog, BfIGb4}

The ligand binding kinetics of recombinantly expressed BflGb4 after $\mathrm{CO}$ photodissociation is biphasic (Figure 5), as previously observed for Ngb and Cygb $[55,56]$. The rapid phase is the competitive binding of $\mathrm{CO}$ and the internal ligand (considered to be the distal E7 histidine of the globin fold), and can be simulated by a bimolecular reaction with $\mathrm{CO}$ and a fixed rate of $4000 / \mathrm{s}$ for the protein ligand. From the slow phase, a rate for histidine dissociation of $2 / \mathrm{s}$ was extracted. This indicates that 


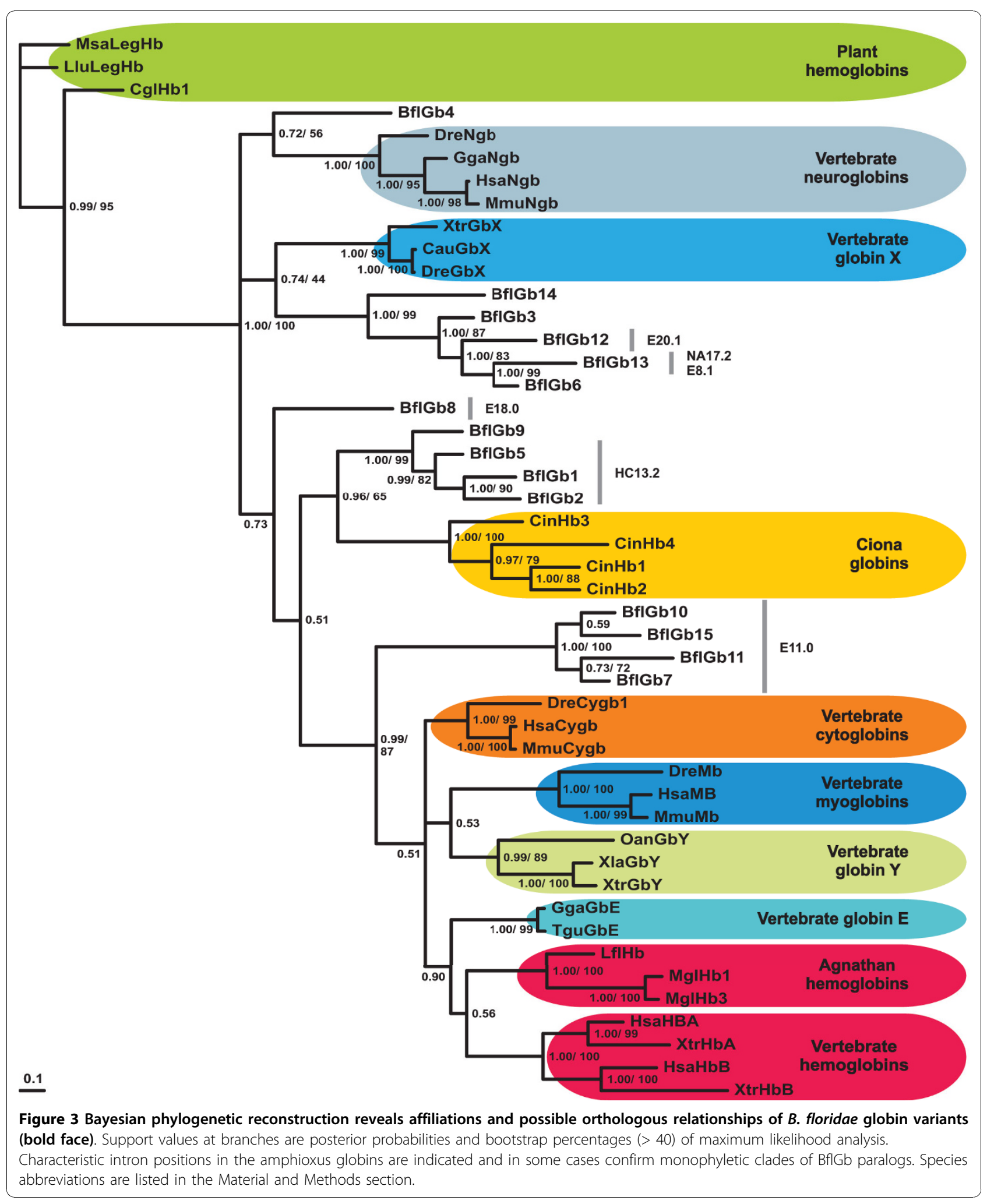




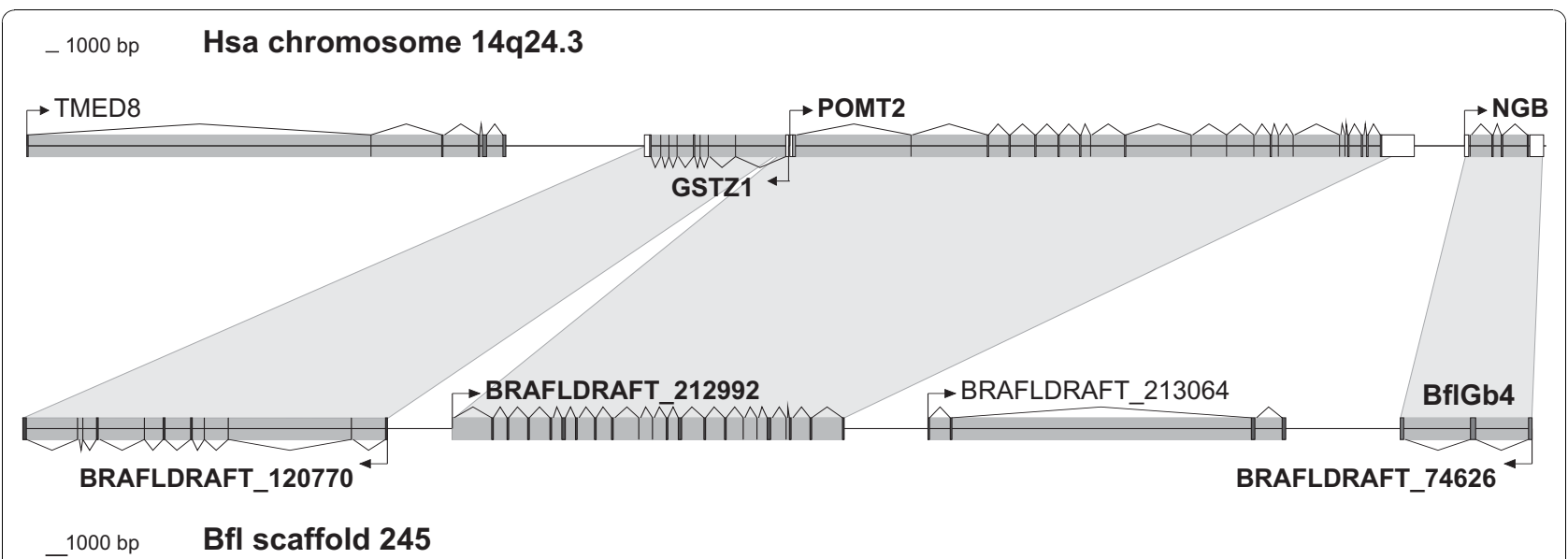

Figure 4 Conserved syntenic relationships of the $B$. floridae genomic region encompassing the $B f I G b 4$ gene and human (Hsa) chromosome 14 , containing the NGB gene.

BflGb4 globin, like its vertebrate ortholog Ngb [55,57], is a hexacoordinated globin, which adopts a His-Fe-His coordination in the absence of external ligands. The hexacoordination of the heme Fe atom in BflGb4 underlines the view that this binding scheme represents an ancestral feature of animal and plant globins, from

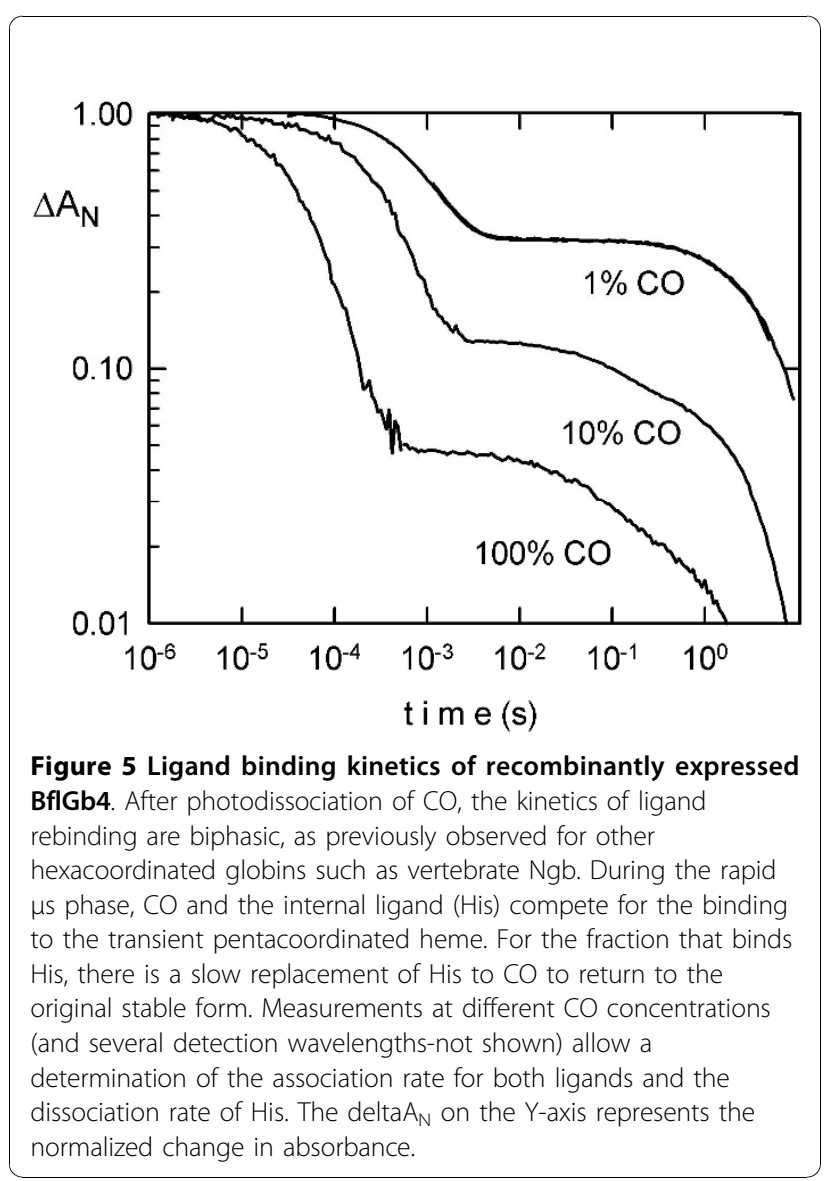

which penta-coordinated globins like $\mathrm{Hb}$ and $\mathrm{Mb}$ evolved [58]. The exact adaptive value of hexacoordination is still unclear. However, it may confer some unusual thermal and acidosis stability to the globin fold $[59,60]$, which could be relevant under environmental or cellular stress.

The $\mathrm{CO}$ and $\mathrm{O}_{2}$ ligand association rates of BflGb4 are quite high (as for Ngb, but not Cygb; [61]), which places the amphioxus globin with Ngb in terms of ligand binding kinetics. The overall oxygen affinity of BflGb4 (oxygen half-saturation value $\mathrm{P}_{50}$ of 3 Torr at $25^{\circ} \mathrm{C}$ ) is about twice that for human NGB (without the disulfide bond [61]), due to a higher intrinsic $\mathrm{O}_{2}$ affinity. However, values are close enough to suggest similar functional roles of the orthologous proteins. In contrast to human NGB, BflGb4 apparently lacks internal cysteine residues, which have been hypothesized to modulate oxygen affinity depending on the cellular redox state [61]. Note that the oxygen affinity for BflGb4 is intermediate to the two allosteric states of human NGB, and there is preliminary evidence in the kinetics of BflGb4 of an additional conformational state. Clearly, further detailed comparisons are needed to extract conserved and taxonspecific features of these globins.

\section{Globin intron evolution and the presence of minisatellites} in amphioxus globin genes

The ancestry and conservation of globins has stimulated studies to trace the evolutionary behavior of introns in these genes, aiming at contributing to the long-standing introns-early versus introns-late debate [18,62-64]. Two introns at positions B12.2 (i. e. between codon positions 2 and 3 of the $12^{\text {th }}$ amino acid of globin helix B) and G7.0 are conserved in all vertebrate globins, in many invertebrate and even plant globin genes. They are therefore thought to have already existed in the globin 
gene ancestor [65]. Both these intron positions can also be found conserved in all 15 amphioxus globin genes (Figure 1, 2). In addition to the strictly conserved B12.2 and G7.0 introns, there are introns at slightly differing positions of the globin E-helix ("central introns") present in globin genes of diverse taxa (vertebrates, invertebrates and plants), which raised speculations on the presence of such a central intron already in the globin ancestor $[18,62]$. Subsequent findings of different E-helix introns in globin genes of closely related insect species casted doubt on this view and argued for an intron gain scenario [64]. Interestingly, the amphioxus globin genes reveal four different intron positions within the E-helix (E8.1, E11.0, E18.0, E20.1; Figure 1 and 2), of which only positions E11.0 (in vertebrate $\mathrm{Ngb}$; [6]) and E18.0 (in nematode globins; $[46,66])$ have been reported before. This situation can in principle be explained by a positional shift of ancestral introns (= "intron sliding"), intron loss or insertional intron gain. Intron sliding, however, is thought to explain only very small intron shifts [23,67]. An intron loss scenario would require many such independent events on several branches of the phylogenetic tree (Figure 3). Therefore, the most parsimonious explanation is that the divergent central intron positions in globin genes in amphioxus and other taxa are due to convergent intron gain. This is corroborated by the lack of a central intron in $B f l G b 4$, the amphioxus ortholog of vertebrate $N g b$. Intron gain may also be responsible for the presence of introns at the unprecedented positions $\mathrm{HC} 13.2$ (between $\mathrm{H}$-helix and C-terminus) in amphioxus globin gene variants $B f l G b 1$, 2 and 5 and intron position NA17.2 (between N-terminus and A helix) in gene BflGb13 (Figure 1).

Detailed annotation of the genomic organization of amphioxus globin genes revealed conspicuous structures, which are interesting with respect to intron evolution. In gene $B f l G b 6$ we observed minisatellite-like tandem duplications, comprising the 3' end of the B12.2 intron and the 5' part of exon 2, while BflGb9 contains a duplicate of the 3 ' boundary of exon 2 (Figure 6).

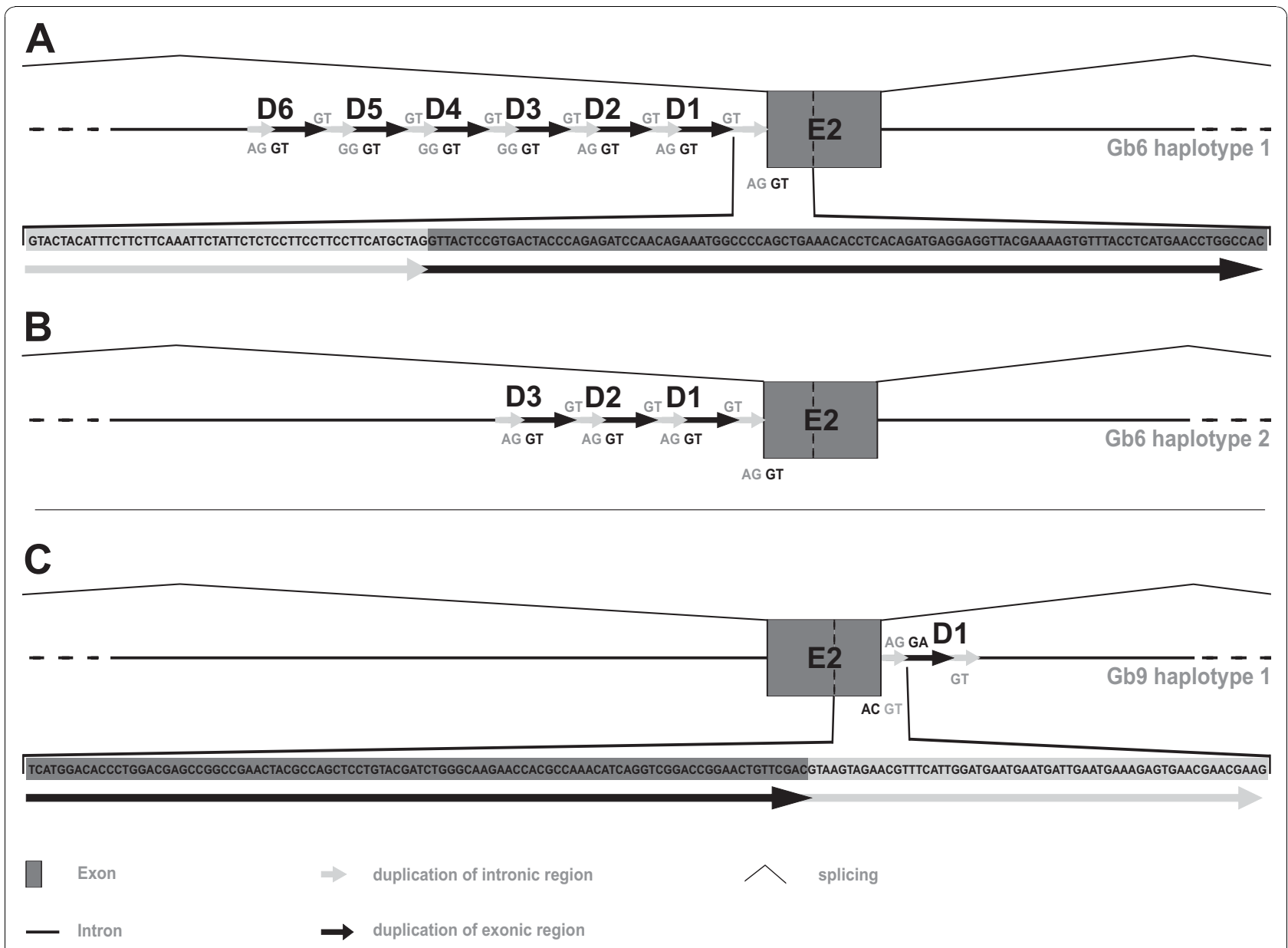

Figure 6 Minisatellite-like tandem duplications of intron/exon boundaries (termed 'mirages') in amphioxus globin genes BfIGb6 (A, haplotype 1; B, haplotype 2) and BflGb9 (C). Note that both, the $5^{\prime}$ and the $3^{\prime}$ boundaries can undergo such duplication events. 
Such tandem repeats spanning an exon-intron boundary have previously been reported in the alcohol dehydrogenase 3 (Adh3) gene of B. floridae and B. lanceolatum and have been termed "mirages" [68]. Other gene loci with similar structures have been reported in amphioxus $[69,70]$, possibly making this a more general phenomenon in cephalochordates. The genomic mechanism of generation of these minisatellites is unclear, and repeat units vary in length (BflGb6: 150-160 bp, BflGb9: 157 bp; Adh3: 10-72 bp, [67]). The Adh3 data as well as our globin RT-PCR results suggest that mirage structures do not interfere with regular splicing of the mRNA, although many, but not all of the tandem repeats contain AG/GT splice signals (for the BflGb6 example, see Figure 6 and Additional file 4) which could be used as cryptic splice sites producing alternative (and possibly aberrant) transcripts. Like other minisatellites, mirage clusters display length instability, possibly due to unequal or intra-strand crossing-overs, and even somatic instability has been detected at the Adh3 locus [68]. For haplotypes 1 and 2 of $B f l G b 6$, we have observed 6 and 3 repeat units, respectively (Figure 6; no second haplotype was found for $B f l G b 9)$. The repeat units of $B f l G b 6$ display between 81 and $100 \%$ nucleotide sequence identity (Additional file 5). Reconstruction of cluster evolution by phylogenetic trees (Additional file 6) reveals typical features of tandem repeat turnover [71], namely concerted evolution within clusters (units D1/D2 of haplotype 2 and D3/D4/D5 of haplotype 1) and exclusion of cluster boundaries (D6/haplotype 1 and D3/haplotype 2) from such intra-allelic homogenization.

With respect to the evolution of introns, mirage repeats immediately offer a suggestive model to explain intron gain within the globin genes over evolutionary times (Figure 7). An exonic part of a repeat unit (e.g. D3) may secondarily turn into a real exon, if its boundary cryptic splice signals are being used. If a suitably positioned splice acceptor site is already present or created by mutation within the original exon 2 , the mirage repeats in between will become intronic. In support of this model, we recognize degenerate tandem repeats within the hypothetically gained intron E8.1 of BflGb13 (Additional file 7). The general idea of intron gain by duplication events encompassing AG/GT proto-splice sites was originally introduced by Rogers [72] and has received renewed interest by studies of intron evolution in ray-finned fishes [73] and mammals [74]. Recently, the systematic examination of six fully sequenced model organism genomes including humans, mouse and Drosophila has emphasized the importance of internal gene duplications as a mechanism for intron generation [75].

\section{Conclusions}

The identification of putative orthologs of vertebrate globin variants $\mathrm{Ngb}, \mathrm{GbX}$ and the $\mathrm{Mb} / \mathrm{Cygb} / \mathrm{Hb}$ lineage in the B. floridae genome emphasizes the particular

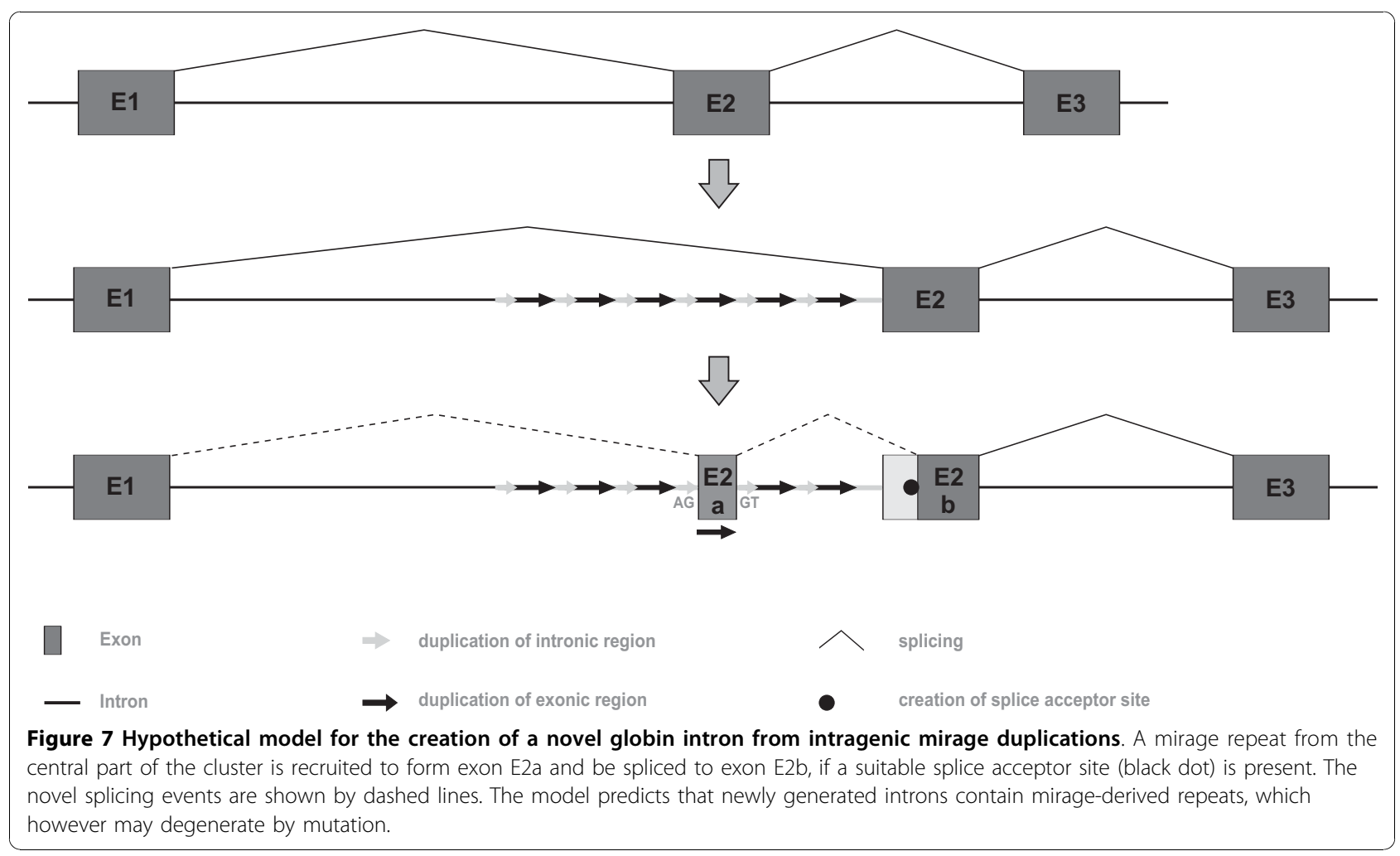


value of cephalochordates as a reference taxon for vertebrate evolution. Although the urochordate lineage may be overall more closely related to vertebrates, the tunicate (C. intestinalis) does not appear to harbour any $1: 1$ orthologs of vertebrate globin genes [28]. The present study facilitates detailed functional studies of the amphioxus globins in order to trace conserved properties and specific adaptations of respiratory proteins at the base of chordate evolution.

\section{Additional material}

Additional file 1: Bayesian phylogenetic reconstruction based on globin alignment including protostome sequences. Lumbricus terrestris globin B (LteGbB [GenBank:P02218]) and globin D (LteGbD [GenBank:P08924), Glycera dibranchiata hemoglobin P3 (GdiHbP3; P23216), Drosophila melanogaster globin 1 (DmeGlob1 [GenBank: AJ132818]), Chironomus thummi hemoglobin VI (CttHbVI [GenBank: P02224]) show paraphyletic distribution and therefore were excluded from the analysis shown in Figure 3. Posterior probabilities are indicated at branches.

Additional file 2: Amino acid similarities (lower half) and identities (upper half) of amphioxus globin variants and selected vertebrate globins.

Additional file 3: Conserved syntenic relationships of the $B$. floridae genomic region encompassing the $B f I G b 3$ gene and human (Hsa) chromosome 14, containing the NGB gene.

Additional file 4: Nucleotide sequence alignment of the minisatellite-like exon/intron boundary duplications (termed 'mirages') of globin gene BfIGb6 haplotype 1 (upper part) and hyplotype 2 (lower part). The light grey line above the alignment shows the intronic part with the splice acceptor site, the darker grey line shows the exonic part of the duplicated structures. Duplicates are designated D1-D6, while the authentic genic sections, which form part of the gene transcripts, are named "E2+intron". Note that the BflGb6 mirage structure from haplotype 1 was reconstructed by us using trace sequence data, while the version within the genome draft appears to be aberrantly assembled.

Additional file 5: Nucleotide sequence identity of mirage repeats from BfIGb6. For designations, see Additional file 4.

Additional file 6: Reconstruction of repeat relationships by a neighbor-joining phylogenetic tree. For designations, see Additional file 4.

Additional file 7: Dot plot nucleotide sequence comparison of the BflGb13 gene region comprising exons 3 and 4 (E3, E4) and the encompassed 'central' E8.1 intron (with itself). Both haplotypes show degenerate repeats in the intron, which might indicate intron origin from mirage-type duplications.

\section{Acknowledgements}

$\mathrm{TH}$ and TB gratefully acknowledge funding by the Deutsche

Forschungsgemeinschaft (DFG Ha2103/3, Bu956/10).

\section{Author details}

${ }^{1}$ Institute of Molecular Genetics, Johannes Gutenberg-University, D-55099

Mainz, Germany. ' Max-Planck Institute of Molecular Genetics, D-14195 Berlin, Germany. ${ }^{3}$ Department of Biochemistry and Molecular Biology, Wayne State University School of Medicine, Detroit, Michigan 48201, USA. ${ }^{4}$ INSERM, U473, F-94276 Le Kremlin Bicetre Cedex, France. ${ }^{5}$ Biocenter Grindel and Zoological Museum, University of Hamburg, D-20146 Hamburg, Germany.

\section{Authors' contributions}

BE carried out the bioinformatic and molecular genetic analyses, and drafted the manuscript. GP performed RT-PCR on amphioxus specimen. LK and MCM performed ligand-binding studies and co-wrote the paper. SV and TB contributed to the initial bioinformatic work of gene identification. TH conceived of the study, and wrote the final version of the manuscript. All authors read and approved this final manuscript.

Received: 28 July 2010 Accepted: 30 November 2010 Published: 30 November 2010

\section{References}

1. Dickerson RE, Geis I: Hemoglobin: structure, function, evolution, and pathology. Benjamin/Cummings, Menlo Park, Calif 1983.

2. Vinogradov SN, Moens L: Diversity of globin function: enzymatic, transport, storage, and sensing. J Biol Chem 2008, 283:8773-8777.

3. Vinogradov SN, Hoogewijs D, Bailly X, Arredondo-Peter R, Gough J, Dewilde S, Moens L, Vanfleteren JR: A phylogenomic profile of globins. BMC Evol Biol 2006, 6:31.

4. Wittenberg JB, Wittenberg BA: Myoglobin-enhanced oxygen delivery to isolated cardiac mitochondria. J Exp Biol 2007, 210:2082-2090.

5. Hendgen-Cotta UB, Merx MW, Shiva S, Schmitz J, Becher S, Klare JP, Steinhoff HJ, Goedecke A, Schrader J, Gladwin MT, Kelm M, Rassaf T: Nitrite reductase activity of myoglobin regulates respiration and cellular viability in myocardial ischemia-reperfusion injury. Proc Natl Acad Sci USA 2008, 105:10256-10261.

6. Burmester $T$, Weich $B$, Reinhardt $\mathrm{S}$, Hankeln $\mathrm{T}$ : A vertebrate globin expressed in the brain. Nature 2000, 407:520-523.

7. Burmester T, Ebner B, Weich B, Hankeln T: Cytoglobin: a novel globin type ubiquitously expressed in vertebrate tissues. Mol Biol Evol 2002, 19:416-421.

8. Trent JT, Hargrove MS: A ubiquitously expressed human hexacoordinate hemoglobin. J Biol Chem 2002, 277:19538-19545

9. Bentmann A, Schmidt M, Reuss S, Wolfrum U, Hankeln T, Burmester T: Divergent distribution in vascular and avascular mammalian retinae links neuroglobin to cellular respiration. J Biol Chem 2005, 280:20660-20665.

10. Mitz SA, Reuss S, Folkow LP, Blix AS, Ramirez JM, Hankeln T, Burmester T: When the brain goes diving: glial oxidative metabolism may confer hypoxia tolerance to the seal brain. Neuroscience 2009, 163:552-560.

11. Schmidt M, Gerlach F, Avivi A, Laufs T, Wystub S, Simpson JC, Nevo E, Saaler-Reinhardt S, Reuss $S$, Hankeln T, Burmester T: Cytoglobin is a respiratory protein in connective tissue and neurons, which is upregulated by hypoxia. J Biol Chem 2004, 279:8063-809.

12. Nakatani $K$, Okuyama H, Shimahara $Y$, Saeki S, Kim DH, Nakajima $Y$, Seki S, Kawada N, Yoshizato K: Cytoglobin/STAP, its unique localization in splanchnic fibroblast-like cells and function in organ fibrogenesis. Lab Invest 2004, 84:91-101.

13. Burmester T, Hankeln T: What is the function of neuroglobin? J Exp Biol 2009, 212:1423-1428.

14. Sun $Y$, Jin K, Peel A, Mao XO, Xie L, Greenberg DA: Neuroglobin protects the brain from experimental stroke in vivo. Proc Natl Acad Sci USA 2003, 100:3497-3500.

15. Khan AA, Wang Y, Sun Y, Mao XO, Xie L, Miles E, Graboski J, Chen S, Ellerby LM, Jin K, Greenberg DA: Neuroglobin-overexpressing transgenic mice are resistant to cerebral and myocardial ischemia. Proc Natl Acad Sci USA 2006, 103:17944-17948.

16. Li D, Chen XQ, Li WJ, Yang YH, Wang JZ, Yu AC: Cytoglobin up-regulated by hydrogen peroxide plays a protective role in oxidative stress. Neurochem Res 2007, 32:1375-1380.

17. Graur D, Li WH: Fundamentals of Molecular Evolution. Sinauer Ass., Sunderland MA, USA; 2000.

18. Hardison RC: A brief history of hemoglobins: plant, animal, protist, and bacteria. Proc Natl Acad Sci USA 1996, 93:5675-5679.

19. Gillemans N, McMorrow T, Tewari R, Wai AW, Burgtorf C, Drabek D, Ventress N, Langeveld A, Higgs D, Tan-Un K, Grosveld F, Philipsen S: Functional and comparative analysis of globin loci in pufferfish and humans. Blood 2003, 101:2842-2849.

20. Fuchs $C$, Burmester T, Hankeln T: The amphibian globin gene repertoire as revealed by the Xenopus genome. Cytogenet Genome Res 2006, 112:296-306 
21. Burmester T, Haberkamp M, Mitz S, Roesner A, Schmidt M, Ebner B, Gerlach F, Fuchs C, Hankeln T: Neuroglobin and cytoglobin: genes, proteins and evolution. IUBMB Life 2004, 56:703-707.

22. Wystub S, Ebner B, Fuchs C, Weich B, Burmester T, Hankeln T: Interspecies comparison of neuroglobin, cytoglobin and myoglobin: sequence evolution and candidate regulatory elements. Cytogenet Genome Res 2004, 105:65-78.

23. Roesner A, Fuchs C, Hankeln T, Burmester T: A globin gene of ancient evolutionary origin in lower vertebrates: evidence for two distinct globin families in animals. Mol Biol Evol 2005, 22:12-20.

24. Patel VS, Cooper SJ, Deakin JE, Fulton B, Graves T, Warren WC, Wilson RK, Graves JA: Platypus globin genes and flanking loci suggest a new insertional model for beta-globin evolution in birds and mammals. BMC Biol 2008, 6:34.

25. Hoffmann FG, Storz JF, Gorr TA, Opazo JC: Lineage-specific patterns of functional diversification in the $\alpha$ - and $\beta$-globin gene families of tetrapod vertebrates. Mol Biol Evol 2010, 27:1126-1138.

26. Delsuc F, Brinkmann H, Chourrout D, Philippe D: Tunicates and not cephalochordates are the closest living relatives of vertebrates. Nature 2006, 439:965-968

27. Putnam N, Butts T, Ferrier DEK, Furlong RF, Hellsten U, Kawashima T, Robinson-Rechavi M, Shoguchi E, Terry A, Yu JK, Benito-Gutiérrez EL, Dubchak I, Garcia-Fernàndez J, Gibson-Brown JJ, Grigoriev IV, Horton AC, de Jong PJ, Jurka J, Kapitonov W, Kohara Y, Kuroki Y, Lindquist E, Lucas S, Osoegawa K, Pennacchio LA, Salamov AA, Satou Y, Sauka-Spengler T, Schmutz J, Shin-I T, Toyoda A, Bronner-Fraser M, Fujiyama A, Holland LZ, Holland PW, Satoh N, Rokhsar DS: The amphioxus genome and the evolution of the chordate karyotype. Nature 2008, 453:1064-1071.

28. Ebner B, Burmester T, Hankeln T: Globin genes are present in Ciona intestinalis. Mol Biol Evol 2003, 20:1521-1525.

29. Bishop JJ, Vandergon TL, Green DB, Doeller JE, Kraus DW: A high-affinity hemoglobin is expressed in the notochord of Amphioxus, Branchiostoma californiense. Biol Bull 1998, 195:255-259.

30. Holland LZ, Albalat R, Azumi K, Benito-Gutierrez E, Blow MJ, BronnerFraser M, Brunet F, Butts T, Candiani S, Dishaw LJ, Ferrier DE, GarciaFernàndez J, Gibson-Brown JJ, Gissi C, Godzik A, Hallböök F, Hirose D, Hosomichi K, Ikuta T, Inoko H, Kasahara M, Kasamatsu J, Kawashima T, Kimura A, Kobayashi M, Kozmik Z, Kubokawa K, Laudet V, Litman GW, McHardy AC, Meulemans D, Nonaka M, Olinski RP, Pancer Z, Pennacchio LA, Pestarino M, Rast JP, Rigoutsos I, Robinson-Rechavi M, Roch G, Saiga H, Sasakura Y, Satake M, Satou Y, Schubert M, Sherwood N, Shiina T, Takatori N, Tello J, Vopalensky P, Wada S, Xu A, Ye Y, Yoshida K, Yoshizaki F, Yu JK, Zhang Q, Zmasek CM, de Jong PJ, Osoegawa K, Putnam NH, Rokhsar DS, Satoh N, Holland PW: The amphioxus genome illuminate vertebrate origins and cephalochordate biology. Genomes Res 2008, 18:1100-1111.

31. Altschul SF, Madden T, Schaffer A, Zhang J, Zhang Z, Miller W, Lipman D: Gapped BLAST and PSI-BLAST: a new generation of protein database search programs. Nucl Acids Res 1997, 25:3389-3402.

32. NCBI trace archive. [http://www.ncbi.nlm.nih.gov/Traces].

33. JGI: Branchiostoma floridae genome project. [http://genome.jgi-psf.org/ Brafl1/Brafl1.home.html].

34. Yu JK, Meulemans D, McKeown SJ, Bronner-Fraser M: Insights from the amphioxus genome on the origin of vertebrate neural crest. Genome Res 2008, 18:1127-1132.

35. A CDNA resource for the cephalochordate amphioxus. Branchiostoma floridae [http://amphioxus.icob.sinica.edu.tw].

36. BLAST: Basic Local Alignment Search Tool. [http://ncbi.nlm.nih.gov/BLAST/ ].

37. Campanella JJ, Bitincka L, Smalley J: MatGAT: an application that generates similarity/identity matrices using protein or DNA sequences. BMC Bioinformatics 2003, 4:29.

38. Ovcharenko I, Loots GG, Hardison RC, Miller W, Stubbs L: zPicture: dynamic alignment and visualization tool for analyzing conservation profiles. Genome Res 2004, 14:472-477.

39. Nakai K, Horton P: PSORT: a program for detecting sorting signals in proteins and predicting their subcellular localization. Trends Biochem Sci 1999, 24:34-36.

40. Bologna G, Yvon C, Duvaud S, Veuthey AL: N-terminal myristoylation predictions by ensembles of neural networks. Proteomics 2004, 4:1626-1632.
41. Huelsenbeck JP, Ronquist F: MRBAYES: Bayesian inference of phylogenetic trees. Bioinformatics 2001, 17:754-755.

42. Ronquist F, Huelsenbeck JP: MRBAYES 3: Bayesian phylogenetic inference under mixed models. Bioinformatics 2003, 19:1572-1574.

43. Whelan S, Goldman N: A general empirical model of protein evolution derived from multiple protein families using a maximum-likelihood approach. Mol Biol Evol 2001, 18:691-699.

44. Abascal F, Zardoya R, Posada D: ProtTest: Selection of best-fit models of protein evolution. Bioinformatics 2005, 21:2104-2105

45. Stamatakis A, Hoover P, Rougemont J: A Rapid Bootstrap Algorithm for the RAxML Web-Servers. Systematic Biology 2008, 75:758-771.

46. Hoogewijs D, De Henau S, Dewilde S, Moens L, Couvreur M, Borgonie G, Vinogradov SN, Roy SW, Vanfleteren JR: The Caenorhabditis globin gene family reveals extensive nematode-specific radiation and diversification. BMC Evol Biol 2008, 8:279.

47. Hankeln T, Amid C, Weich B, Niessing J, Schmidt ER: Molecular evolution of the globin gene cluster $\mathrm{E}$ in two distantly related midges, Chironomus pallidivittatus and C. thummi thummi. J Mol Evol 1998, 46:589-601.

48. Imamura T, Baldwin TO, Riggs A: The amino acid sequence of the monomeric hemoglobin component from the bloodworm, Glycera dibranchiata. J Biol Chem 1972, 247:2785-2797.

49. Frenkel MJ, Dopheide TAA, Wagland BM, Ward CW: The isolation, characterization and cloning of a globin-like, host-protective antigen from the excretory-secretory products of Trichostrongylus colubriformis. Mol Biochem Parasitol 1992, 50:27-36.

50. Blaxter ML: Nemoglobins-divergent nematode globins. Parasitology Today 1993, 9:353-360.

51. Springer BA, Sligar SG, Olson JS, Phillips GN Jr: Mechanisms of Ligand Recognition in Myoglobin. Chem Rev 1994, 94:699-714.

52. Hardison RC: Globin genes on the move. J Biol 2008, 7:35.

53. Wetten OF, Nederbragt AJ, Wilson RC, Jakobsen KS, Edvardsen RB, Andersen $\varnothing$ : Genomic organization and gene expression of the multiple globins in Atlantic cod: conservation of globin-flanking genes in chordates infers the origin of the vertebrate globin cluster. BMC Evol Biol 2010, 10:315.

54. Churcher AM, Taylor JS: Amphioxus (Branchiostoma floridae) has orthologs of vertebrate odorant receptors. BMC Evol Biol 2009, 9:242

55. Dewilde S, Kiger L, Burmester T, Hankeln T, Baudin-Creuza V, Aerts T, Marden MC, Caubergs R, Moens L: Biochemical characterization and ligand binding properties of neuroglobin, a novel member of the globin family. J Biol Chem 2001, 276:38949-55.

56. Pesce A, Bolognesi M, Bocedi A, Ascenzi P, Dewilde S, Moens L, Hankeln T, Burmester T: Neuroglobin and cytoglobin. Fresh blood for the vertebrate globin family. EMBO Rep 2002, 12:1146-51.

57. Pesce A, Dewilde S, Nardini M, Moens L, Ascenzi P, Hankeln T, Burmester T, Bolognesi M: Human brain neuroglobin structure reveals a distinct mode of controlling oxygen affinity. Structure 2003, 11:1087-95.

58. Hoy JA, Robinson H, Trent JT, Kakar S, Smagghe BJ, Hargrove MS: Planthemoglobins: a molecular fossil record for the evolution of oxygen transport. J Mol Biol 2007, 371:168-79.

59. Hamdane D, Kiger L, Dewilde S, Uzan J, Burmester T, Hankeln T, Moens $L$, Marden MC: Hyperthermal stability of neuroglobin and cytoglobin. FEBS $J$ 2005, 272:2076-84.

60. Picotti P, Dewilde S, Fago A, Hundahl C, De Filippis V, Moens L, Fontana A: Unusual stability of human neuroglobin at low $\mathrm{pH}$-molecular mechanisms and biological significance. FEBS J 2009, 276:7027-39.

61. Hamdane D, Kiger L, Dewilde S, Green BN, Pesce A, Uzan J, Burmester T, Hankeln T, Bolognesi M, Moens $L$, Marden MC: The redox state of the cell regulates the ligand binding affinity of human neuroglobin and cytoglobin. J Biol Chem 2003, 278:51713-21.

62. Gö M: Correlation of DNA exonic regions with protein structural units in haemoglobin. Nature 1981, 291:90-92.

63. Stoltzfus A, Doolittle WF: Slippery introns and globin gene evolution. Curr Biol 1993, 3:215-217.

64. Hankeln T, Friedl H, Ebersberger I, Martin J, Schmidt ER: A variable intron distribution in globin genes of Chironomus: evidence for recent intron gain. Gene 1997, 205:151-160.

65. Dixon B, Pohajdak B: Did the ancestral globin gene of plants and animals contain only two introns? Trends Biochem Sci 1992, 17:486-488.

66. Hunt PW, McNally J, Barris W, Blaxter ML: Duplication and divergence: the evolution of nematode globins. J Nematol 2009, 41:35-51. 
67. Stoltzfus A, Logsdon JM Jr, Palmer JD, Doolittle F: Intron "sliding" and the diversity of intron positions. Proc Natl Acad Sci USA 1997, 94:10739-10744

68. Canestro C, Roser GD, Albalat R: Minisatellite instability at the Adh locus reveals somatic polymorphism in amphioxus. Nucl Acids Res 2002, 30:2871-2876.

69. Dalfó D, Cañestro C, Albalat R, Gonzàlez-Duarte R: Characterization of a microsomal retinol dehydrogenase gene from amphioxus: retinoid metabolism before vertebrates. Chem Biol Interact 2001, 130-132, 359-370.

70. Martínez-Mir A, Cañestro C, Gonzàlez-Duarte R, Albalat R: Characterization of the amphioxus presenilin gene in a high gene-density genomic region illustrates duplication during the vertebrate lineage. Gene 2001, 279:157-164.

71. Dover G: Molecular drive: a cohesive mode of species evolution. Nature 1982, 299:111-117.

72. Rogers JH: How were introns inserted into nuclear genes? Trends Genet 1989, 5:213-216

73. Venkatesh B, Ning Y, Brenner S: Late changes in spliceosomal intron define clades in vertebrate evolution. Proc Natl Acad Sci USA 1999 96:10267-10271.

74. Zhuo D, Madden R, Elela SA, Chabot B: Modern origin of numerous alternatively splices human introns from tandem arrays. Proc Natl Acad Sci USA 2007, 104:882-886.

75. Gao X, Lynch M: Ubiquitous internal gene duplication and intron creation in eukaryotes. Proc Natl Acad Sci USA 2009, 106:20818-20823.

doi:10.1186/1471-2148-10-370

Cite this article as: Ebner et al:: The globin gene family of the cephalochordate amphioxus: implications for chordate globin evolution. BMC Evolutionary Biology 2010 10:370

\section{Submit your next manuscript to BioMed Central and take full advantage of:}

- Convenient online submission

- Thorough peer review

- No space constraints or color figure charges

- Immediate publication on acceptance

- Inclusion in PubMed, CAS, Scopus and Google Scholar

- Research which is freely available for redistribution

Submit your manuscript at www.biomedcentral.com/submit 